\title{
Implementasi Remote Monitoring Pada Virtual Private Server Berbasis Telegram Bot API (Studi Kasus Politeknik TEDC Bandung)
}

\author{
Mamay Syani ${ }^{1}$, Bayu Saputro ${ }^{2}$ \\ Teknik Informatika, Politeknik TEDC Bandung \\ J1.Politeknik-Pesantren KM.2 Cibabat Cimahi Utara Kota Cimahi 40513 \\ 1'msyani@poltektedc.ac.id ${ }^{1)},{ }^{2}$ bayu190198@gmail.com \\ Diterima : 23 Februari 2021 \\ Disetujui : 28 Maret 2021
}

\begin{abstract}
Virtual Private Server (VPS) merupakan layanan server yang menggunakan teknologi bare metal hypervisor untuk membagi hardware server fisik menjadi beberapa server virtual yang di hosting di infrastruktur fisik yang sama. Virtualisasi menawarkan kemudahan untuk meng-host beberapa server pada satu server fisik. Setiap server dapat memiliki layanan dan sistem operasi yang berbeda satu sama lain. Dimana permasalahan yang sering terjadi disebuah institusi pendidikan seperti di Politeknik TEDC, dalam implementasi teknologi (VPS) kurangnya awareness terhadap ancaman dari pihak dalam dan luar, sehingga perlunya pengawasan yang terintergasi dengan seorang system administrator. Melihat permasalahan tersebut dengan menggunakan tools zabbix sebagai network monitoring system dasboard memiliki fitur map dan grafik sehingga membantu dalam proses pengawasan, pengaturan dan administrasi pada sistemnya, zabbix memiliki fitur Application Programming Interface (API) Bot yang diintegrasikan dengan aplikasi telegram, yaitu sistem perpesanan lintas platform yang berpusat pada keamanan dan privasi keamanan dan privasi pemakainya berbasis cloud. Permasalahan yang sering terjadi di Politeknik TEDC dengan populasi pengguna mahasiswa 1874 orang dan 146 dosen di tambah karyawan dan staff mencapai 100 orang, dalam pemanfaatan akses sistem informasi oleh civitas Politeknik TEDC, seorang admin dalam mengelola (VPS) terdapat masalah seperti kurangnya sumber daya manusia terutama seorang system administrator yang bertugas mengawasi kinerja server sehingga kurang dapat melakukan pengamatan (VPS) selama 24 jam. Implementasi Bot API sudah banyak digunakan dengan keunggulan dalam keandalan untuk menyediakan data ke user yang tidak terbatas oleh waktu. Penggunaan pemantauan mengintegrasikan fungsi Application Programming Interface (API) telegram ke dalamnya untuk dapat mengirim pesan dan memeriksa secara realtime seperti Informasi problem alerts, user login, active host, memory, cpu dan hdd status ditunjukan dalam satuan percent, serta detail total kapasitas, available dan used.
\end{abstract}

Kata Kunci: Virtual Private Server ( VPS), Remote Monitoring, Zabbix, Bot, API, Telegram,.

\section{PENDAHULUAN}

Virtual Private Server (VPS) adalah layanan server yang menggunakan teknologi bare metal hypervisor untuk membagi hardware server fisik menjadi beberapa server virtual yang di hosting di infrastruktur fisik yang sama

Politeknik TEDC merupakan salah satu perguruan tinggi vokasi yang berada di wilayah Jawa Barat, dengan jumlah dosen, mahasiswa dan tenaga non kependidikan mencapai 2120 orang berdasarkan dari dari PDPT dan Sister Kemdikbud, dengan di implementasikannya sistem informasi terintegrasi, baik untuk aplikasi e-learning, sistem informasi dosen, sistem informasi akademik, PDPT dan sistem informasi pendukung lainnya dengan teknologi traditional IT infrastructure, di gunakan untuk firewall menggunakan Mikrotik RouterOS sebagai dan remote monitoring SNMP (Simple Network Management Protocol) yang digunakan pada 
teknologi yang sedang berjalan. Pada infrasturktur jaringan yang digunakan sering terjadi kendala pada layanan seperti aplikasi pada web server, terjadi gagal akses, seorang system administrator yang bertugas mengawasi server di Politeknik TEDC, tidak memiliki seseorang yang khusus di bidang jaringan server sehingga system administrator yang bertugas untuk menangani infrastruktur jaringan dan virtual private server (VPS) Politeknik TEDC masih menggunakan pihak ketiga dan untuk yang menangani IT infrastruktur tidak berada di ruangan server ataupun memantau server secara langsung.

Solusi yang akan di impelemnatsikan yaitu menggunakan tools zabbix yang salah satu software open source yang dapat digunakan untuk memonitor jaringan, dan status dari berbagai network services, servers dan network hardware lainnya. Pemantuan jaringan dengan kemampuan untuk merekam statistik jaringan dengan konsep Simple Network Management Protocol (SNMP). Dengan zabbix, pengguna dapat mudah mengetahui status server, kondisi jaringan dan mendapatkan notifikasi jika terjadi gangguan, dengannya fitur zabbix alerts dan sudah mendukung polling dan trapping.

Berdasar uraian diatas pada penulisan ini bermaksud melakukan penelitian dengan judul "Implementasi Remote Monitoring Pada Virtual Private Server Berbasis Telegram Bot API (Studi Kasus Politeknik TEDC Bandung)".

\section{LANDASAN TEORI}

\section{A. Penelitian Terkait}

Menurut Anggiat Cokrojoyo, Justinus Andjarwirawan, dan Agustinus Noertjahyana dalam penelitian mengenai pembuatan Bot Telegram untuk, mengambil informasi dan jadwal film menggunakan API mengatakan bahwa dengan bot maka pengguna hanya butuh untuk mengirimkan perintah ke akun Bot dan jadwal jam tayang atau informasi yang diinginkan akan langsung diberikan ke pengguna yang membutuhkan.[1]

Menurut David Karismata W. Tion dan Indrastanti R. Widiasari dalam penelitian mengenai perancangan Bot untuk remote monitoring pada server menggunakan Telegram Bot API, untuk mengatasi human error dalam proses pengawasan terutama server, seorang system administrator yang bertanggung jawab dalam mengamati kinerja server selama 24 jam, dibutuhkan layanan yang dapat melakukan proses remote monitoring untuk menambah fleksibilitas serta dapat melakukan monitoring terhadap server secara real time apabila terjadi masalah pada jaringan Bot akan mengirim notifikasi kepada pengelola layanan jaringan.[2]

Menurut Dwi Wijonarko dalam penelitiannya mengenai zabbix network monitoring sebagai perangkat monitoring jaringan di SKPD Kota Malang dengan menggunakan zabbix, proses monitoring jaringan komputer dapat dilakukan tanpa harus berada dalam lingkup jaringan, bisa dimonitor jarak jauh dimanapun dan kapanpun selama agent masih terhubung ke internet.[8]

\section{B. Virtual Private Server}

Sebuah teknologi virtualisasi sistem operasi dan perangkat lunak yang memungkinkan sebuah mesin dengan kapasitas besar dibagi ke beberapa virtual mesin. Tiap virtual mesin ini melayani sistem operasi dan perangkat lunak secara dedicated. VPS juga dapat diartikan sebagai sebuah metode untuk mempartisi atau membagi resource sebuah server menjadi beberapa server virtual. Virtual machine tersebut memiliki kemampuan menjalankan sistem operasi sendiri seperti layaknya sebuah server. Bahkan pengguna dapat mengelola sebuah virtual machine secara terpisah, dari hypervisor os server utama. Untuk mengendalikan VPS (Virtual Private Server) pada sistem operasi Windows menggunakan protocol RDP (Remote Desktop Protocol) dengan port TCP/UDP 3389 , sedangkan sistem operasi Linux menggunakan SSH (Secure shell) dengan port default TCP/UDP 22, apabila menggunakan

VPS dilengkapi dengan control panel untuk mengelola script, users, pemrosesan, file sistem backup restore dan fitur lainnya, VPS bekerja seperti sebuah server yang terpisah memiliki processes, users, files dan menyediakan full root access. Setiap VPS mempunyai IP address, port number, tables, filtering dan routing rules sendiri. VPS juga dapat melakukan konfigurasi file untuk sistem dan software service.

Dengan VPS pengguna tidak perlu lagi merawat server virtual, karena penyedia VPS akan merawat secara berkala serta melakukan upgrade operating system, system backup, dan sebagainya secara berkala.[5]

\section{Remote Monitoring}

Remote monitoring atau RMON adalah suatu teknik untuk melakukan pemantauan kondisi jaringan. Pemantaun jaringan ini sangat terkait dengan traffic atau lalu lintas data pada 
infrastuktur jaringan baik menggunakan traditional IT infrastructure dan. Remote Monitoring atau RMON pada awalnya dikembangkan untuk mengatasi masalah manajemen segmen situs dan Local Area Network (LAN) dari lokasi terpusat. Standar $R M O N$ menentukan sekelompok fungsi dan statistik yang dapat dipertukarkan antara network probes yang kompatibel dengan $R M O N$ dan console managers. RMON melakukan deteksi kesalahan jaringan yang luas dan menyediakan data penyesuaian kinerja untuk $N A s$.

$R M O N$ mengumpulkan sembilan jenis informasi, termasuk bytes sent, packets sent, packets dropped dan statistics by host. NAs menggunakan $R M O N$ untuk menentukan lalu lintas pengguna jaringan atau tingkat bandwidth dan informasi akses situs web. RMON menggunakan perangkat jaringan tertentu, seperti server, dan berisi aplikasi manajemen jaringan yang berfungsi sebagai client. RMON mengontrol jaringan dengan menggunakan protocol remote $T C P / U D P$ dan aplikasinya secara bersamaan. Ketika sebuah paket jaringan ditransmisikan, RMON memfasilitasi penglihatan status paket dan memberikan informasi lebih lanjut, dalam hal suatu paket diblokir, dihentikan atau hilang.[6]

\section{Telegram}

Telegram adalah aplikasi pesan instant berbasis cloud yang fokus pada kecepatan dan keamanan. Telegram dirancang untuk memudahkan pengguna saling berkirim pesan teks, audio, video, gambar dan stiker dengan aman. Secara default, seluruh konten yang ditransfer akan dienkripsi berstandar internasional. Dengan demikian, pesan yang terkirim sepenuhnya aman dari pihak ketiga, bahkan dari telegram sekalipun. Bukan hanya teks, gambar dan video, telegram juga bisa jadi sarana user mengirimkan dokumen, file multimedia, berkas, berbagi lokasi real-time dan kontak yang tersimpan di perangkat ke orang lain. asal, orang yang dituju juga mempunyai aplikasi dengan akun telegram terdaftar di perangkatnya. Telegram juga merupakan aplikasi yang ringan, cepat, tidak ada iklan, dan gratis selamanya. Lalu user bisa menggunakan telegram dengan menggunakan PC dan laptop via web browser. Kelebihan lainnya dari telegram yaitu dapat dimanfaatkan di dunia bisnis dan komunitas karena berbasis cloud.
Karena telegram berbasis cloud, maka penggunanya dapat mengakses pesan dari perangkat yang berbeda secara bersamaan dan membagikan jumlah berkas yang tak terbatas hingga ukuran 1,5GB. Berkas ini dapat diatur untuk disimpan di dalam perangkat atau hanya di cloud.[7]

\section{E. Zabbix}

Zabbix adalah salah satu software open source yang dapat digunakan untuk memonitor jaringan, dan status dari berbagai network services, servers dan network hardware lainnya. Software diciptakan oleh Alexei Vladishev. dengan zabbix, pengguna dapat mudah mengetahui status server, kondisi jaringan dan mendapatkan notifikasi jika terjadi gangguan dan masalah, zabbix juga sudah mendukung polling dan trapping.

Tools ini menggunakan GPL license open source, sudah memiliki fitur GUI yang memudahkan pemakaian para pengguna, beberapa fitur yang ada berupa map dan grafik sehingga membantu pengaturan administrasi dengan mudah. Dengan menampilkan map jaringan komputer admin kelola beserta dengan statusnya. Maka admin pun akan tahu kondisi jaringan jika terjadi masalah. warna hijau menandakan status kondisi normal sedangkan warna merah jika terjadi masalah.

Untuk tipe laporan, pengguna dapat membuatnya sesuai waktu yang diinginkan, per minggu, bulan atau sesuai jangka waktu lainnya. Dilihat dari sisi keamanannya, software ini sudah mempunyai sistem authentifikasi dengan IP address dan memberikan informasi masalah dengan cepat, misalkan dengan e-mail atau sms dan Bot API.

Salah satu cara kerja zabbix akan memonitoring beban dari $C P U$ yang sedang dipantau dan apabila beban dari $C P U$ melebihi standar yang telah diatur maka zabbix akan mengirim aksi notifikasi secara otomatis.[3]

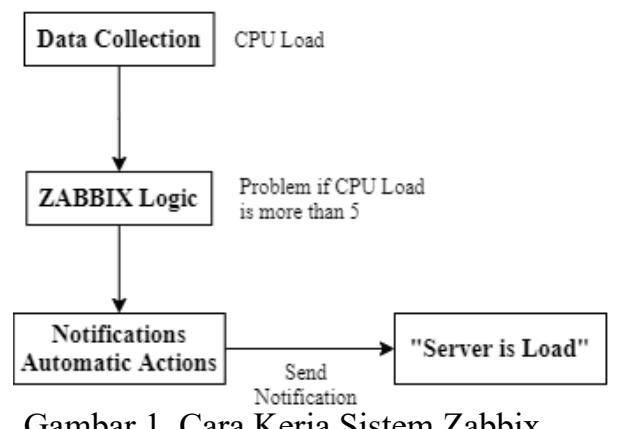

Gambar 1. Cara Kerja Sistem Zabbix 


\section{METODE PENELITIAN}

Metode yang digunakan dalam penelitian ini menggunakan metode NDLC (Network Development Life Cycle).[9]

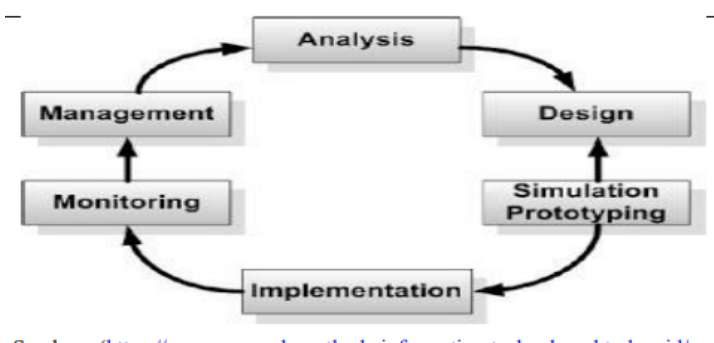

Sumber : (https://www.research-methods-information-technology.html.co.id

Gambar 2. Alur Network Development Life Cycle

Tahapan pada Network Development Life Cycle (NDLC).[9]

1. Tahap Analysis

Tahap awal ini dilakukan analisa kebutuhan, analisa permasalahan yang muncul, analisa keinginan user, dan analisa topologi atau jaringan yang sudah ada saat ini.

2. Tahap Design

Tahap desain ini akan membuat gambar desain topologi jaringan yang akan dibangun. Desain bisa berupa design structure topology, design access data, desain tata layout perkabelan, dan sebagainya yang akan memberikan gambaran jelas tentang proyek yang akan dibangun.

3. Tahap Simulation Prototype

Pada tahap ini beberapa network engineer akan membuat dalam bentuk simulasi dengan bantuan tools khusus di bidang network seperti BOSON, Packet Tracer, NETSIM, dan sebagainya.

4. Tahap Implementation

Dalam tahap implementasi network engineer akan menerapkan semua yang telah direncanakan dan di desain sebelumnya.

5. Tahap Monitoring

Tahapan monitoring merupakan tahapan yang penting agar jaringan dapat berjalan sesuai dengan keinginan dan tujuan dari user pada tahap awal analisis

6. Tahap Management

Pada tahap ini suatu kebijakan perlu dibuat untuk membuat atau mengatur agar sisem yang telah dibangun dapat berjalan dengan baik dan dapat berlangsung lama.

\section{A. Analisis Sistem}

Berdasarkan data yang diperoleh, infrastruktur jaringan yang digunakan Politeknik TEDC Bandung telah menggunakan fiber optik dengan provider ASTINet dengan untuk server dedicated memiliki 5 IP public 1:1 downstream dan upstream 3 MBps, yaitu untuk IP Public yang digunakan sebagai gateway, IP server PDPT Kemdikbud, IP server akademik lama, IP server akademik baru, dan untuk layanan Sister dosen. Teknologi fiber optik yang digunakan adalah GPON ZTE dengan menggunakan MikroTik RouterBoard 2011UiAS-2HnD sebagai Firewall.

Server dedicated yang digunakan yaitu Dell PowerEdge T30 Mini Tower Server, Dell PowerEdge T20 Mini Tower Server, Rainer Server dengan sistem operasi yang digunakan adalah Windows yang di pasang Hypervisor Oracle VirtualBox untuk menjalankan Linux Ubuntu Server,

\section{B. Analisis Kebutuhan}

Berdasarkan hasil observasi yang dilakukan di Politeknik TEDC Bandung, maka sistem yang akan dibangun memiliki spesifikasi perangkat keras seperti ditunjukkan pada tabel 1 dan perangkat lunak ditunjukan pada tabel 2 .

Tabel 1 Perangkat keras VPS Bot API

\begin{tabular}{|c|c|c|}
\hline No & Perangkat & VPS \\
\hline 1 & Processor & $2 v C P U s$ \\
\hline 2 & Memory & $4 \mathrm{~GB}$ \\
\hline 3 & $H D D$ & $80 \mathrm{~GB}$ \\
\hline
\end{tabular}

Tabel 2 Perangkat lunak VPS Bot API

\begin{tabular}{|c|c|c|l|}
\hline No & Software & Versi & \multicolumn{1}{|c|}{ keterangan } \\
\hline 1 & $\begin{array}{l}\text { Ubuntu } \\
\text { Server }\end{array}$ & 16.04 .5 & $\begin{array}{l}\text { Sistem operasi } \\
\text { yang akan } \\
\text { digunakan di } \\
\text { VPS }\end{array}$ \\
\hline 2 & $\begin{array}{l}\text { Zabbix } \\
\text { Server }\end{array}$ & 4.0 & $\begin{array}{l}\text { Aplikasi } \\
\text { Monitoring } \\
\text { Server }\end{array}$ \\
\hline 3 & MySQL & 10.1 .29 & $\begin{array}{l}\text { Sistem } \\
\text { penyimpanan } \\
\text { data konfigurasi }\end{array}$ \\
\hline
\end{tabular}

\section{Usulan Pemecahan Masalah}

Dengan hasil penelitian yang dilakukan di Politeknik TEDC maka diajukan usulan untuk mengatasi permasalahan yang ditemukan yaitu dengan mengimplementasikan zabbix sebagai sistem pemantau kinerja server untuk mempermudah admin dalam proses pemantuan kinerja server dengan bantuan Bot API Telegram untuk notifikasi sistem, solusi yang dapat diberikan adalah: 
a. Sistem pemantauan yang di implementasikan dapat mempermudah dalam melakukan pemantauan kinerja server dengan web GUI.

b. Saat terjadi masalah pada sistem akan mengirim notifikasi jenis masalah yang terjadi kepada admin jaringan melalui aplikasi telegram.

c. Admin jaringan dapat memonitoring kinerja server dengan menggunakan kata kunci yang sudah terprogram pada Bot API Telegram.

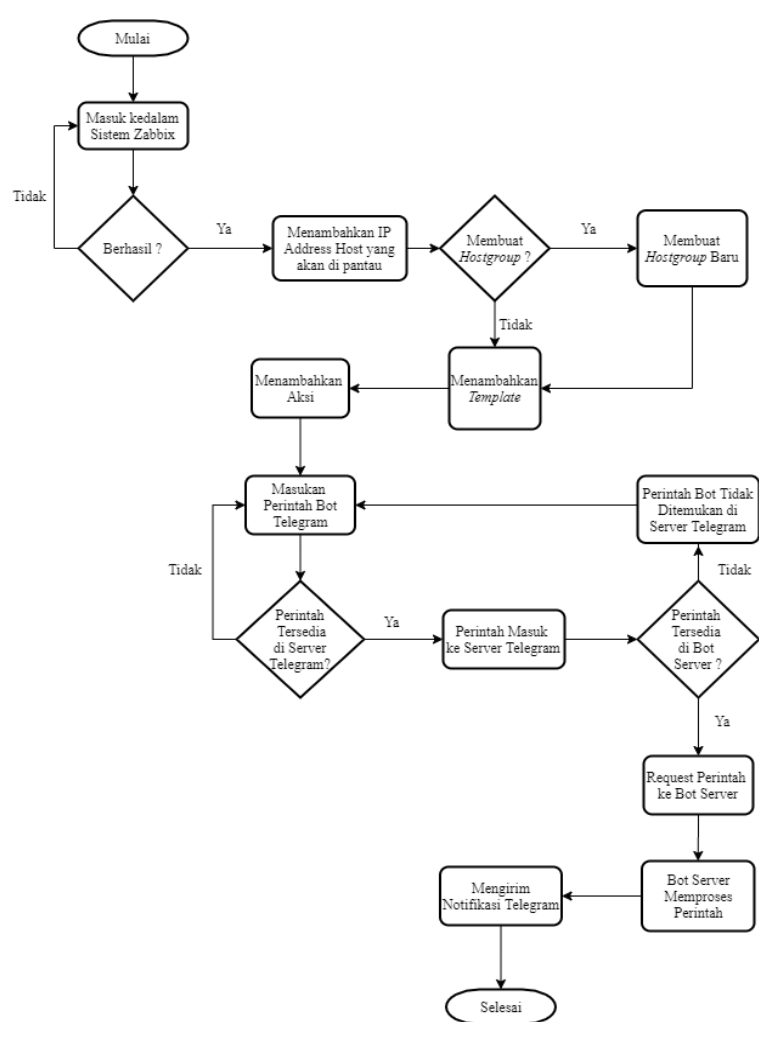

Gambar 3. Flowchart Sistem Keseluruhan

Pada gambar 3 mengambarkan dari keseluruhan rancangan yang akan diimplementasikan pada sistem zabbix server, dimulai dari masuk kedalam sistem Zabbix melalui web Graphical User Interface (GUI) sampai mengirimkan notifikasi kepada admin jaringan berupa pesan menggunakan media Bot API telegram.

\section{Daftar Kata Kunci Telegram Monitoring}

Ada beberapa kata kunci yang sudah dirancang oleh penulis dan dapat digunakan oleh admin jaringan untuk memonitoring keadaan server ditunjukan pada tabel 3 .
Tabel 3 Daftar Kata Kunci Bot API Telegram

\begin{tabular}{|c|l|l|}
\hline No & \multicolumn{1}{|c|}{ Kata Kunci } & \multicolumn{1}{|c|}{ Penjelasan } \\
\hline 1 & users & $\begin{array}{l}\text { Kata kunci ini untuk } \\
\text { menampilkan semua } \\
\text { nama pengguna yang } \\
\text { sudah terdaftar pada } \\
\text { sistem zabbix. }\end{array}$ \\
\hline 2 & /host & $\begin{array}{l}\text { Kata kunci ini untuk } \\
\text { menampilkan nama klien, } \\
\text { alamat ip address, dan } \\
\text { port yang sudah terdaftar } \\
\text { pada sistem zabbix. }\end{array}$ \\
\hline 3 & $/$ cpu & $\begin{array}{l}\text { Kata kunci ini untuk } \\
\text { menampilkan informasi } \\
\text { tentang kinerja memori } \\
\text { yang sedang berjalan pada } \\
\text { server. }\end{array}$ \\
\hline 4 & $/ h d d$ & $\begin{array}{l}\text { Kata kunci ini untuk } \\
\text { menampilkan informasi } \\
\text { tentang penggunaan } \\
\text { media penyimpanan yang } \\
\text { dipakai. }\end{array}$ \\
\hline
\end{tabular}

\section{HASIL DAN PEMBAHASAN}

\section{A. Kode Program 1}

Inisialisasi Token dan Koneksi Database Zabbix Server

\begin{tabular}{|c|}
\hline $\begin{array}{l}\text { 1. from_future_import print_function } \\
\text { 2. import psutil } \\
\text { 3. import telebot } \\
\text { 4. import mysql.connector } \\
\text { 5. mydb = mysql.connector.connect( } \\
\text { 6. host = 'localhost', user = 'root', } \\
\text { 7. passwd='password', database = 'zabbixdb') } \\
\text { 8. sql=mydb.cursor() } \\
\text { 9. api='1221808221:AAHRTOAp4ybERrrYdA } \\
\text { qbb2fJBH71eDXE1Gk' } \\
\text { 10. chat_id='1251599434' } \\
\text { 11. bot = telebot.TeleBot(api) }\end{array}$ \\
\hline
\end{tabular}

Sesuai dengan perancangan sistem yang telah dibuat, untuk menghubungkan Bot $A P I$ Telegram dengan sistem dibutuhkan token API yang merupakan kunci untuk mengakses bot. Chat_id adalah indentitas yang digunakan untuk bot mengirim pesan dan mydb digunakan sebagai kunci untuk mengakses database zabbix server.

\section{B. Kode Program 2}

Koneksi Bot API Telegram dengan Sistem zabbix server

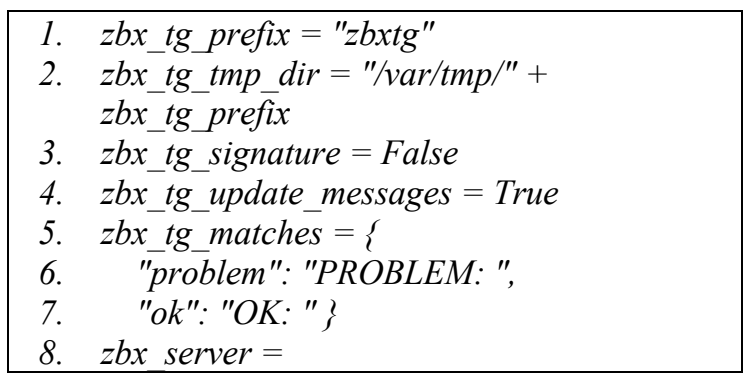




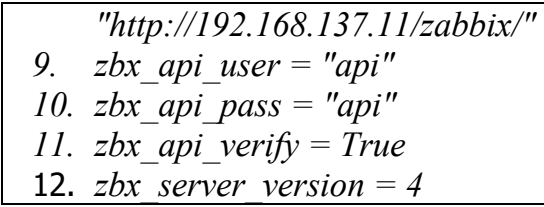

Kode program 2 menjelaskan fungsi untuk bot telegram dapat mengakses ke sistem zabbix server sehingga Bot API telegram dapat mengirim notifikasi kepada admin jaringan ketika terjadi masalah dengan server.

\section{Kode Program 3}

Fungsi Users

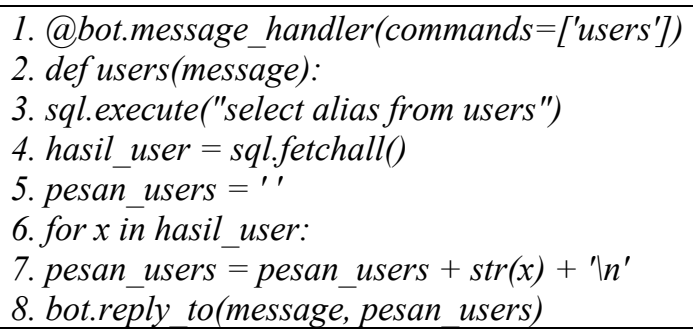

Kode program 3 menjelaskan fungsi ketika admin jaringan ingin mengetahui nama pengguna yang sudah terdaftar untuk mengakses sistem zabbix server dan Bot API telegram akan mengirim informasi tersebut dengan mengakses database sistem.

\section{Kode Program 4}

Fungsi Host

1. @bot.message_handler(commands=['host'])
2. definterface(message):
3. $\quad$ sql.execute("select host, ip, port from hosts
inner join interface on
hosts.hostid=interface.hostid;")
4. hasil_interface $=$ sql.fetchall()
5. pesan_interface =',
6. for $x$ in hasil_interface:
7. pesan_interface = pesan_interface + str $(x)$
$+n^{\prime}$

Kode program 4 merupakan fungsi untuk menampilkan alamat ip address dan port klien yang sudah terhubung dengan sistem zabbix server dengan mengakses database sistem.

\section{E. Kode Program 5 Fungsi $C P U$}

1. @bot.message_handler(commands $\left.=\left[{ }^{\prime}{ }^{\prime} p u^{\prime}\right]\right)$
2. definterface(message):
3. cpu = psutil.virtual_memory()
4. $\quad$ total = cpu.total

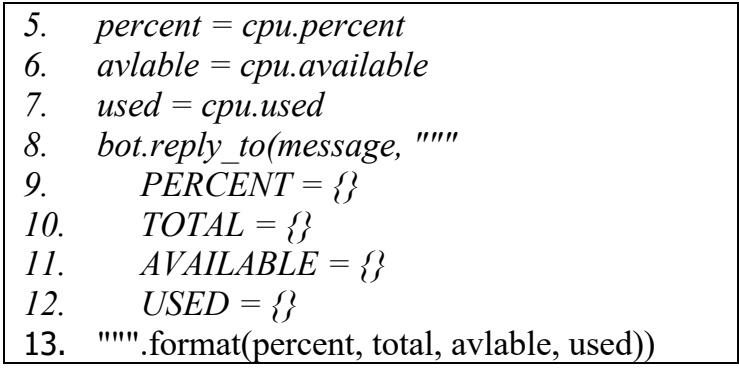

Kode program 5 merupakan fungsi untuk menampilkan informasi dari kinerja memory server yang sedang berjalan.

\section{F. Kode Program 6 \\ Fungsi $H D D$}

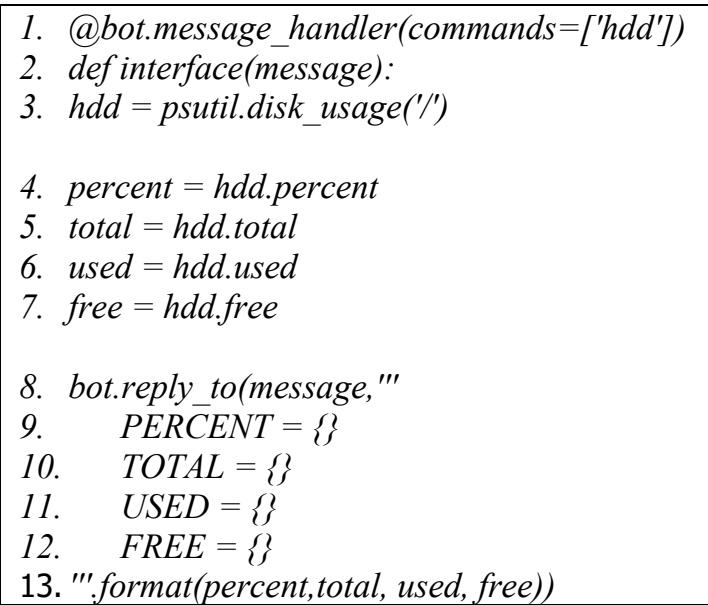

13. '"'.format(percent,total, used, free))

Kode program 6 berfungsi untuk menampilkan informasi tentang pemakaian harddisk atau media penyimpanan data server.

\section{G. Pengujian Notifikasi Bot API Telegram}

Untuk pengujian notifikasi Bot API telegram penulis menguji dengan membuat stres server dan client, penulis juga menganti hostname client. Pada gambar 4 memperlihatkan bahwa zabbix server kinerja terlalu tinggi dan zabbix agent telah mengganti informasi (hostname).

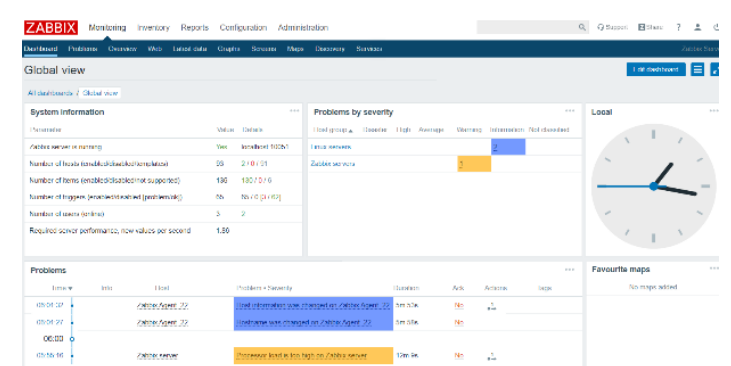

Gambar 4. Tampilan Menu Dashboard Ketika Terjadi Masalah 
Pada gambar 5 menampilkan bot telegram mengirim pesan yang berisi informasi yaitu nama masalah yang sedang terjadi dan waktu terjadinya masalah tersebut.

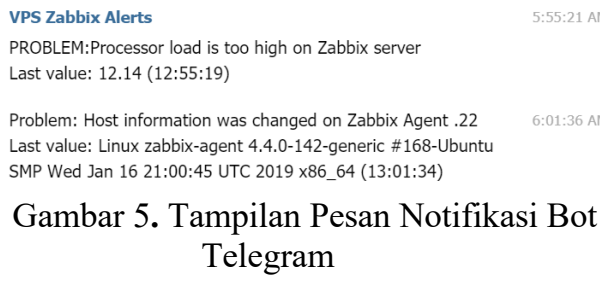

Pada gambar 6 menampilkan tampilan apabila masalah yang terjadi sudah selesai diperbaiki maka Bot telegram akan mengirim pesan yang berisi bahwa masalah yang terjadi pada server atau klien sudah diperbaiki.

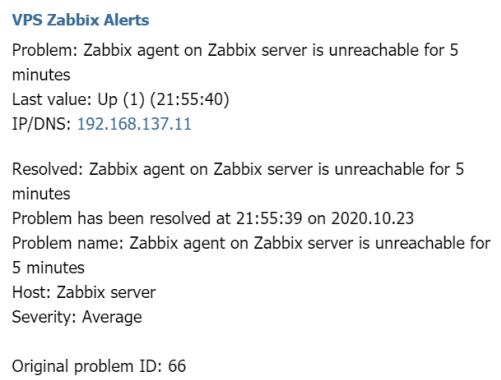

Gambar 6. Tampilan Pesan Notifikasi Bot Telegram Masalah Selesai Diperbaiki

\section{H. Pengujian Program Bot API Telegram}

Pada gambar 7 menampilkan tampilan nama pengguna yang sudah terdaftar pada sistem zabbix server dengan menggunakan kata kunci /users di percakapan dengan Bot telegram.

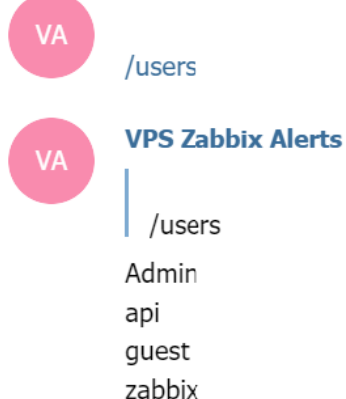

Gambar 7. Pengujian Kata Kunci /users di Telegram

Pada gambar 8 menampilkan tampilan nama klien, alamat ip address, dan port yang digunakan di sistem zabbix server dengan menggunakan perintah /host di percakapan dengan Bot telegram.

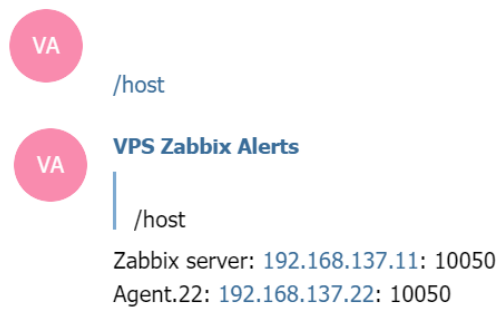

Gambar 8. Pengujian Kata Kunci /host di Telegram

Pada gambar 9 menampilkan tampilan dari berapa persen memori yang sedang berjalan, total memori yang dipasang di server, total memori yang tersedia, dan total memory yang terpakai oleh server.

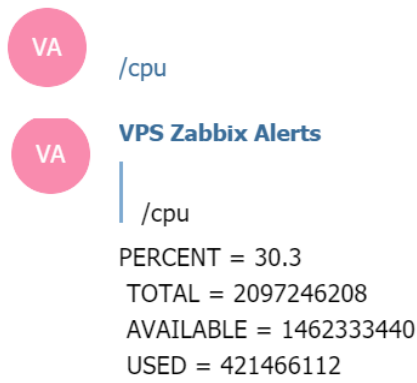

Gambar 9. Pengujian Kata Kunci /cpu di Telegram

Pada gambar 10 menampilkan tampilan berapa persen pengunaan harddisk server, total harddisk yang digunakan di server, dan total harddisk yang tersisa untuk menyimpan data.

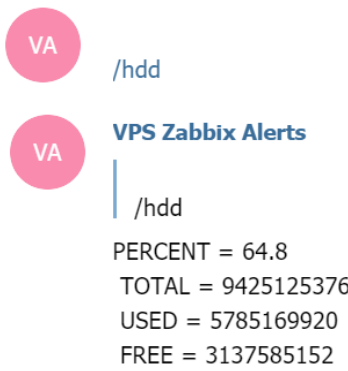

Gambar 10. Pengujian Kata Kunci /hdd di Telegram

\section{SIMPULAN}

Setelah melakukan pengujian terhadap sistem zabbix secara langsung, maka dapat disimpulkan bahwa dengan memanfaatkan aplikasi Bot API telegram bisa membantu system administrator jaringan ketika tidak berada di tempat pengawasan server dan dapat mengetahui keadaan server yang diawasi dengan aplikasi telegram yang di install di smartphone tanpa membuka PC (Personal Computer) ataupun 


\section{Jurnal Sistem Komputer dan Kecerdasan Buatan \\ Vol. IV No. 2 Tahun 2021}

membuka laptop, hal ini ditunjukan dengan sistem monitoring jaringan menggunakan sistem zabbix baik zabbix server ataupun zabbix agent berhasil dibangun. Pada pengujian sistem zabbix apabila terjadi masalah maka dashboard zabbix akan menampilkan informasi client yang mengalami masalah dan apabila masalah tersebut termasuk dengan pemicu notifikasi maka akan terkirim kepada system administrator dengan menggunakan perintah pada Bot API telegram. Pada pengujian perintah pada program bot telegram berhasil menampilkan beberapa informasi dari server yaitu nama user yang dapat mengakses sistem zabbix server, informasi nama client beserta alamat IP address client, informasi yang di tampilkan yaitu kinerja pemakaian ram atau memory dari server utama, lalu menampilkan informasi total penggunaan media penyimpanan data pada harddik dan penggunaan uptime Central Processing Unit (CPU) kinerja pada server dan logs pada server.

\section{DAFTAR PUSTAKA}

[1] Cokrojoyo, A., Andjarwirawan, J., \& Noertjahyana, A. (2017). Pembuatan Bot Telegram Untuk Mengambil Informasi dan Jadwal Film Menggunakan PHP. Jurnal Infra, 5(1), 224-227, Program Studi Teknik Informatika Fakultas. http://studentjournal.petra.ac.id/index.php/te knik-informatika/article/view/5163

[2] David Karismata W. Tion, \& Widiasari, I. R. (2016). Perancangan Bot untuk Remote Monitoring pada Server menggunakan Telegram Bot API. https://repository.uksw.edu/bitstream/12345 6789/11449/2/T1_672012109_Full text.pdf

[3] Diro, S. (2015). System Monitoring Virtual Menggunakan Zabbix. Retrieved January 22, 2019, https://www.slideshare.net/kasbecker5/syste m-monitoring-zabbix

[4] ICT. (2014). Pengertian RMON (Remote Network Monitoring). Retrieved January 22, 2019 , from https://www.proweb.co.id/articles/ict/rmon.h tml

[5] Lukman. (2017). Apa itu Virtual Private Server (VPS)? Dan Apa Aja Sih Kegunaannya? Retrieved January 22, 2019, from https://www.cloudmatika.co.id/2017/04/25/a pa-itu-virtual-private-server/

[6] Techopedia. (2019). Remote Monitoring (RMON). Retrieved January 21, 2019, from https://www.techopedia.com/definition/2484 4/remote-monitoring-rmon

[7] Winarso, B. (2016). Sejarah dan Fitur-fitur Andalan Aplikasi Telegram. Retrieved September 8, 2019, from https://dailysocial.id/post/apa-itu-telegram

[8] Wijonarko, D. (2014). Zabbix Network Monitoring Sebagai Perangkat Monitoring Jaringan Di. Jurnal ELTEK, 12(1), 27-38. Retrieved from http://eltek.polinema.ac.id/index.php/eltek/ar ticle/view/31/31

[9] Anggorowati, O. P. D., Kurniawan, M. T., \& Yunan, U. (2015). Desain dan Analisa Infrastruktur Jaringan Wireless di PDII-LIPI Jakarta dengan Menggunakan Metode Network Development Life Cycle (NDLC). eProceedings of Engineering, 2(2). 